\title{
Delayed access to emergency obstetrical care among preeclamptic and non- preeclamptic women in Port-Au-Prince, Haiti
}

Katharine Hutchinson ${ }^{{ }^{*}}$ D , Malcolm Bryant ${ }^{2}$, Mary Bachman DeSilva ${ }^{3}$, Deborah Price ${ }^{4}$, Lora Sabin ${ }^{2}$, Lindsay Bryson ${ }^{5}$, Roger Jean Charles $^{6}$ and Eugene Declercq ${ }^{2}$

\begin{abstract}
Background: The primary objective of this comparative, cross-sectional study was to identify factors affecting delays in accessing emergency obstetric care and clinical consequences of delays among preeclamptic and nonpreeclamptic women in Port-au-Prince, Haiti.

Methods: We administered 524 surveys to women admitted to the Médecins Sans Frontières Centre de Référence en Urgences Obstétricales (CRUO) obstetric emergency hospital. Survey questions addressed first (at home), second (transport) and third (health facility) delays; demographic, clinical, and behavioral risk factors for delay; and clinical outcomes for women and infants. Bivariate statistics assessed relationships between preeclampsia status and delay, and between risk factors and delay.

Results: We found longer delays to care for preeclamptic women (mean $14.6 \mathrm{~h}, \mathrm{SD} 27.9$ versus non-preeclamptic mean $6.8 \mathrm{~h}$, SD 10.5, $p<0.01$ ), primarily attributable to delays before leaving for hospital (mean $13.4 \mathrm{~h}, \mathrm{SD} 30.0$ versus non-preeclamptic mean 5.5 h, SD 10.5). Few demographic, clinical, or behavioral factors were associated with care access. Poor outcomes were more likely among preeclamptic women and infants, including intensive care unit admission (10.7\%, vs. $0.5 \%$ among non-preeclamptic women, $p<0.01)$ and eclampsia ( $10.7 \%$ vs. no cases, $p<0.01)$ for women, and neonatal care unit admission ( $45.6 \%$ vs. $15.4 \%, p<0.01)$ and stillbirth $(9.9 \%$ vs. $0.5 \%, p<0.01)$. Longer delays among both groups were not associated with poorer clinical outcomes.
\end{abstract}

Conclusion: Pregnant women with preeclampsia in Port-au-Prince reported significant delays in accessing emergency obstetric care. This study provides clear evidence that hospital proximity alone does not mitigate the long delays in accessing emergency obstetrical care for Haitian urban, poor women.

Keywords: Maternal mortality, Neonatal mortality, Obstetrics, Urban health

\section{Background}

Despite progress in reducing maternal mortality, Haiti still suffers from some of the worst maternal and neonatal health indicators in the Western Hemisphere. Hypertensive disorders of pregnancy, including preeclampsia and eclampsia, are particularly prevalent, $[1,2]$ and are the leading cause of pregnancy-related death in the region [3].

\footnotetext{
* Correspondence: katharinehutchinson@gmail.com

${ }^{1}$ Médecins Sans Frontières and Boston University School of Public Health,

715 Albany Street, Boston 02118 USA

Full list of author information is available at the end of the article
}

An understaffed, underfunded health system with few obstetric providers, exacerbated by several large natural disasters in the past decade, makes access to health care difficult. Although most hospitals and obstetric staff are concentrated in the capital city of Port-au-Prince, [4] access to emergency obstetric care is challenging even in this urban context.

Thaddeus and Maine's Three Delays Model of maternal mortality describes how delays at home prior to deciding to seek care (the first delay); delays in finding and managing transport to a facility (the second delay); and

(c) The Author(s). 2018 Open Access This article is distributed under the terms of the Creative Commons Attribution 4.0 International License (http://creativecommons.org/licenses/by/4.0/), which permits unrestricted use, distribution, and 
delays in receiving appropriate treatment once at the facility (the third delay) contribute to maternal mortality [5]. The model was conceptualized to address the experiences of rural women, with the original article titled "Too Far to Walk." Past studies utilizing the Three Delays Model have identified several factors associated with delays in various contexts, including distance to facility, [6-8] cost, [8] educational level, [8] women's status in the family, [9] perception of the gravity of the situation, [10] transportation options, [11] distribution of facilities, and perception of quality at the facility. [12, 13] Relatively few studies, [14-17] however, have examined how women in urban contexts access emergency care, and the unique delays they encounter. One such study in Kenya examined how access and outcomes among urban poor women may be even worse than their rural counterparts [14]. Urban women who develop obstetric complications, such as preeclampsia and eclampsia, need timely access to high-quality obstetric care to prevent dangerous complications, but often face specific barriers to access that are unique to these settings. The goal of this study was to examine the delays faced by women with preeclampsia while accessing emergency obstetric care in urban Port-au-Prince, the relative importance of the factors associated with delays, and the relationship between those delays and maternal and neonatal health outcomes.

\section{Methods}

\section{Study setting}

Haiti's public health system suffers from inadequate funding, insufficient trained health staff, and severe shortages of medications and supplies [18]. Demographic and Health Survey (DHS) data indicate that although most pregnant Haitian women accessed antenatal care, the majority reported difficulties accessing care for problems during pregnancy [19].

Médecins Sans Frontières (MSF) operates the Centre de Référence en Urgences Obstétricales (CRUO) emergency obstetric hospital in Port-au-Prince, which admits more than 500 women per month with complications of pregnancy or delivery. CRUO does not offer antenatal care, though women who deliver at the facility are followed up with postpartum visits. More than a quarter of the admitted women have preeclampsia or eclampsia [20]. CRUO is the only large facility in Port-au-Prince offering free obstetric services. Because CRUO is an emergency referral hospital, women with no specific risk factors of pregnancy are generally not admitted, unless delivery is imminent.

\section{Study procedures}

We conducted a study on delays to access emergency obstetric care for preeclamptic and non-preeclamptic pregnant women admitted to the CRUO hospital. This paper reports the quantitative findings from the larger mixed methods study. We utilized a design consisting of a quantitative survey and medical records review to examine delays to care among preeclamptic and non-preeclamptic women; demographic, clinical and behavioral risk factors for delay to care; and the association between delay to care and poor maternal and neonatal clinical consequences.

\section{Inclusion and exclusion criteria}

All women who delivered a baby at CRUO and had a medical diagnosis of preeclampsia or eclampsia, or normal pregnancy, were eligible for the study. CRUO admitting staff determined whether women met the diagnostic criteria. Women who were unconscious and admitted to the Intensive Care Unit and met all inclusion criteria were also included via interviews with their legal representatives. To ensure consistency with the non-preeclamptic group, who all delivered during the hospitalization, the preeclamptic group was also limited to women who delivered. Women admitted to CRUO after delivery for postpartum or gynecologic problems were also ineligible. Non-preeclamptic participants included those women admitted to CRUO with a diagnosis of "physiologic labor" merely because delivery was imminent.

\section{Measures and data collection methods}

The survey recorded self-reported clinical pregnancy history, information about the onset of the symptoms that prompted the decision to leave, how long it took to leave home after the decision to leave was made, the type and cost of transport used, the number and location of other health centers visited prior to CRUO, and the time it took to reach the health center. The time each patient spent in the triage unit prior to admission was recorded from the medical chart.

To ensure that women who died during labor or after delivery were not excluded from the analysis, which could bias study results, women were identified for inclusion at admission to CRUO. Women were identified for inclusion at admission to CRUO, but were not approached for written consent until after delivery and once their medical condition was stable and they were medically able to provide consent and participate. Women were interviewed after delivery, before their discharge from CRUO. The survey was administered to the postpartum patient herself, or in cases of death or severe medical disability, to a legal representative who could give written consent. Study personnel administered surveys verbally in private settings in Haitian Creole or French, depending on the participant's preference. After survey administration, a medical records review, including maternal and infant outcomes, was completed for each participant by the same study personnel who had completed the survey. These secondary outcomes were 
recorded from the chart to reduce any reporting bias on the part of the participants, who may have not been able to report medical terminology. Study recruitment and data collection occurred between November 2014 and January 2015.

\section{Sample size considerations}

The sample size was calculated using delay to care as the outcome. The population-based DHS, conducted in 2012, showed that almost $75 \%$ of urban pregnant women in Haiti experienced a difficulty accessing health care during their most recent pregnancy. We expected that women with complications of pregnancy at CRUO had a similar likelihood of delay to care, regardless of whether or not they were diagnosed with preeclampsia. Distance to the nearest health center was found in one study in rural Haiti to be the largest factor in access to prenatal care. We assumed that distance to the hospital would be the most important factor in delay to emergency obstetric care. We also assumed that $20 \%$ of women lived more than an hour away from the hospital, a conservative estimate given the logistical challenges of travel in Port au Prince. Further, it seemed reasonable to presume that: a) this prevalence would likely be similar between women diagnosed with preeclampsia and women with low-risk pregnancies and b) women not exposed to this risk factor (living far away) would have a lower risk of delay, estimated at a $50 \%$.

We measured the exposed group, the women who live far away, by the amount of time they took to reach the hospital, by whichever method they chose to come. Women who took one hour or longer to reach the hospital (whether by walking, public transit, or other means), were categorized as "exposed". Therefore, the "unexposed" group comprised women whose travel time to the hospital in this instance was less than one hour.

The sample size was calculated to show differences in delayed access to care between the women exposed to a behavioral, demographic or clinical risk factor, and those who did not have a risk factor. Thus, we used the following assumptions for the calculation of the sample size: 1 ) two-sided significance level of $95 \% ; 2$ ) power of the study $80 \%$; 3$)$ ratio of unexposed/exposed (4:1); 4) expected relative risk of delayed access in the exposed group 1.5; 5) expected proportion of outcome in unexposed group $50 \%$. This generated a sample size calculation of 42 women in the exposed group (women who live far away) and 168 women in the unexposed group (women living close to the hospital), a total of 210 women.

The planned sample size for the survey was 420 women (210 women in each group, preeclamptic and non-preeclamptic), designed to show differences for each group in access to care between women with the primary risk factor (longer distance from the hospital, based on prior literature) and those without the risk factor. Because about $30 \%$ of preeclamptic women were not able to report on either the first or second delay due to sickness or eclampsia, an additional 82 preeclamptic women were added, for a total of 292 preeclamptic participants and a grand total of 502 women, assuming a similar rate of non-response regarding first or second delays among the added participants.

\section{Outcome measures}

The primary outcome, total delay, represents the length of time between the onset of labor or complications, and the administration of appropriate treatment at the hospital. If the time was greater than six hours, it was classified as a delay, based on UNFPA recommendations [21]. We recorded delay as a continuous variable so that the association of delay with clinical outcomes could also be investigated as a dose-response relationship. The relationship between risk factors and delay was also evaluated for very long delay $(>24 \mathrm{~h})$, and extremely long delay $(>72 \mathrm{~h})$.

\section{Analytic methods}

We used bivariate analysis to assess the association between delayed access to emergency obstetric care (exposure) and clinical result (outcome). Findings are presented as relative risks with $95 \%$ confidence intervals $(\mathrm{CI})$. The analysis also examined relationships between clinical, demographic, and behavioral risk factors and delay. When sample sizes were too small for separate analysis of subgroups (e.g. only 27 women had university education), categories were collapsed. We calculated the association between each individual antecedent risk factor (exposures) and delayed access to health care (outcome). Results were then stratified by preeclampsia status. Statistical analyses were conducted using JMP, Version 11 (SAS Institute Inc., Cary, North Carolina).

The study was approved by the Institutional Review Board of Boston University Medical Center, the Ethics Review Board of Médecins Sans Frontières, and the Haiti Ethics Review Board.

\section{Results}

\section{Background characteristics of survey respondents}

Five hundred and two women were initially enrolled, but twenty-two women were withdrawn because they were unable to complete most survey questions. These women had suffered eclamptic seizures and were unable to remember enough information about the events prior to their hospitalization to answer survey questions.

Background characteristics of the entire sample are presented in Table 1. There were no significant differences in multiparity between the preeclamptic and non-preeclamptic participants. Most women who 
Table 1 Demographic and behavioral characteristics of study participants, by preeclampsia status

\begin{tabular}{|c|c|c|c|}
\hline & Non-preeclamptic n (\%) & Preeclamptic n (\%) & $p$-value \\
\hline & $n=210$ & $n=292$ & \\
\hline Mean age (SD) & $27.2(6.2)$ & $29.7(6.8)$ & $<0.01$ \\
\hline Married or cohabitating & $149(71.3)$ & $223(76.4)$ & 0.20 \\
\hline Attended some secondary school or university & $152(73.1)$ & $206(71.3)$ & 0.66 \\
\hline Employed in formal sector & $15(7.4)$ & $16(5.6)$ & 0.43 \\
\hline Had religious affiliation & $184(88.0)$ & $276(95.2)$ & $<0.01$ \\
\hline Owned home & $64(30.5)$ & $138(47.3)$ & $<0.01$ \\
\hline Internally displaced & $1(0.5)$ & $8(2.8)$ & 0.04 \\
\hline "Doing well" or "good" (reported economic status)" & $12(5.8)$ & $25(8.7)$ & 0.22 \\
\hline $\mathrm{ANC}^{2}$ with health professional & $203(96.7)$ & $281(96.2)$ & 0.80 \\
\hline Adequate ANC (4+ visits) & $171(84.2)$ & $231(83.1)$ & 0.74 \\
\hline Diagnosis of preeclampsia in current pregnancy & $15(7.2)$ & $136(46.9)$ & $<0.01$ \\
\hline Birth plan made with health professional ${ }^{3}$ & $191(91.0)$ & $258(89.0)$ & 0.35 \\
\hline Birth plan made with TBA & $35(16.6)$ & $38(13.0)$ & 0.18 \\
\hline ANC with TBA & $43(20.6)$ & $61(20.9)$ & 0.77 \\
\hline Remembered any preeclampsia danger signs & $31(14.8)$ & $93(31.9)$ & $<0.01$ \\
\hline Any medications taken in pregnancy & $193(91.9)$ & $266(91.1)$ & 0.34 \\
\hline Medications prescribed by health professional & $191(91.0)$ & $267(91.8)$ & 0.20 \\
\hline Antihypertensive medications reported & $0(0)$ & $38(13.0)$ & $<0.01$ \\
\hline Did not remember the name of medications taken & $86(41.0)$ & $102(34.9)$ & 0.17 \\
\hline
\end{tabular}

"Economic status self-reported via four-item scale using locally appropriate terminology, choices included "doing well", "good", "not too bad" and "no money"

${ }^{2} \mathrm{ANC}=$ Antenatal care. $\mathrm{DHS}=$ Demographic and Health Surveys. TBA = Traditional birth attendant

${ }^{3}$ Birth plans refer to a discussion between provider and patient about intentions and plans for birth

participated in this study were married, had a religious affiliation, had completed at least primary school education, and were not formally employed. Few study participants $(7.3 \%)$ self-reported "doing well" or "good" in terms of socioeconomic status.

Similar proportions of women who delivered preterm (32-36 weeks gestation) and very preterm $(<32$ weeks gestation) reported attending four antenatal care (ANC) visits as did women who delivered at term (84.0\% of all women, data not shown). Almost half (46.9\%) of preeclamptic women had received a diagnosis of preeclampsia prior to their admission to CRUO, along with $7.2 \%$ of women in the non-preeclamptic group. However, less than one third (31.9\%) of preeclamptic women could recall any danger sign of worsening preeclampsia, such as headache or facial swelling, although some of the preeclampsia diagnoses may have been made by the referral facility at the time of the labor and birth.

\section{Delay to accessing obstetric care}

Table 2 summarizes findings relating to the Three Delays [5].

Preeclamptic women experienced a longer mean total delay in accessing emergency obstetrical care than non-preeclamptic women $(14.6 \mathrm{~h}$ versus $6.8 \mathrm{~h}, p<0.01)$. The median total delay was five hours for preeclamptic women, and four hours for non-preeclamptic women ( $<<$ 0.01 ). Longer delays among the preeclamptic group were attributable primarily to waiting longer to leave home (first delay) and a slightly longer third delay. When evaluated as a dichotomous variable (delay $>6 \mathrm{~h}$ versus $\leq 6 \mathrm{~h}$ ), a larger proportion of preeclamptic women reported a long delay compared to non-preeclamptic women (43.8\% vs. $33.5 \%, p=0.03)$. Almost one-fifth $(17.0 \%)$ of preeclamptic women reported a delay of twenty-four hours or more before receiving care.

Mean delays for preeclamptic women were longer than median delays due to a portion of cases with extraordinary delays. Twenty-four preeclamptic participants experienced delays longer than $48 \mathrm{~h}$, and for thirteen of those women, the delay was longer than $72 \mathrm{~h}$. An analysis of women with extremely long delays $(>72 \mathrm{~h})$ showed that most had developed preeclampsia earlier in pregnancy. A greater proportion of these women were admitted preterm $(84.6 \%$ versus $38.6 \%$ of all preeclamptic women, $p<0.01$ ), and had a low birth weight baby ( $83.3 \%$ versus $46.3 \%$ of all preeclamptic women, $\mathrm{p}<0.01$ ), than women in the preeclampsia subgroup overall. 
Table 2 First, Second, Third, and Total Delay in Preeclamptic and Non-Preeclamptic groups

\begin{tabular}{|c|c|c|c|}
\hline & Non-Preeclamptic & Preeclamptic & $p$-value \\
\hline First Delay (hours) & $n=207$ & $n=285^{a}$ & \\
\hline $\begin{array}{l}\text { Mean (standard } \\
\text { deviation, SD) }\end{array}$ & $5.5(10.5)$ & $13.4(30.0)$ & $<0.01$ \\
\hline $\begin{array}{l}\text { Median } \\
\text { (interquartile } \\
\text { range, IQR) }\end{array}$ & $3.0(5.0)$ & $2.0(12.0)$ & \\
\hline $\begin{array}{l}\text { Second Delay } \\
\text { (hours) }\end{array}$ & $n=194$ & $n=251$ & \\
\hline Mean (SD) & $1.0(0.6)$ & $1.2(1.0)$ & 0.20 \\
\hline Median (IQR) & $1.0(0)$ & $1.0(0)$ & \\
\hline $\begin{array}{l}\text { Third Delay } \\
\text { (minutes) }\end{array}$ & $n=208$ & $n=292$ & \\
\hline Mean (SD) & $11.6(38.1)$ & $49.7(60.2)$ & $<0.01$ \\
\hline Median (IQR) & $0(0)$ & $35.0(70.0)$ & \\
\hline Total Delay (hours) & $n=191$ & $n=235$ & \\
\hline Mean (SD) & $6.8(10.5)$ & $14.6(27.9)$ & $<0.01$ \\
\hline Median (IQR) & $4(5.0)$ & $5(10.6)$ & \\
\hline
\end{tabular}

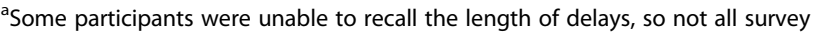
respondents are included in the analysis of each delay

\section{Maternal and neonatal outcomes}

More than $10 \%$ of preeclamptic women and almost half of infants experienced poor clinical outcomes. For women, preeclampsia was associated with greater likelihood of cesarean section, intensive care unit admission, coma, eclampsia, and transfusion, compared to non-preeclamptic women (Table 3). Almost one in nine (10.7\%) preeclamptic women also experienced an eclamptic seizure. For newborns, a preeclampsia diagnosis for their mothers was associated with greater likelihood of neonatal care unit (NICU) admission, stillbirth, low birth weight $(<2.5 \mathrm{~kg})$, and APGAR score less than 7 at 5 min of life (Table 3). There were 30 total stillbirths in the study, 29 of which occurred to women with preeclampsia.

\section{Risks for delay}

We found few significant associations between any of the demographic, clinical, or behavioral risk factors and total delay, regardless of whether the delay was measured as binary or continuous. Adequate antenatal care was associated with shorter delays, but only for non-preeclamptic women (data not shown). Living farther from the hospital was not associated with longer delays. In the preeclampsia group, women living in the neighborhood where CRUO is located and the adjacent neighborhood had significantly longer delays (data not shown).

\section{Risks for poor clinical outcomes by length of delay}

Longer total delays were not associated with poorer clinical outcomes (Table 4), except for a greater likelihood of stillbirth among preeclamptic women with shorter delays compared to those with longer delays $(14.5 \%$ versus $5.9 \%)$. Stillbirths were associated with delivering at earlier gestational ages (32 weeks versus 37 weeks, $p<0.01$, data not shown).

\section{Discussion}

Urban, poor women in Haiti face dangerous delays to accessing emergency obstetric care. Preeclamptic and eclamptic women in this study experienced a delay in receiving appropriate medical treatment of more than fourteen hours, on average. Median delays were much

Table 3 Distribution of poor maternal and neonatal outcomes for non-preeclamptic and preeclamptic women

\begin{tabular}{|c|c|c|c|c|}
\hline & $\begin{array}{l}\text { Non-preeclamptic } \\
\text { n (\%) }\end{array}$ & $\begin{array}{l}\text { Preeclamptic } \\
\text { n (\%) }\end{array}$ & $\begin{array}{l}\text { Relative risk associated } \\
\text { with preeclampsia } \\
\text { exposure }(95 \% \mathrm{Cl})\end{array}$ & $p$-value \\
\hline & $n=210$ & $n=292$ & & \\
\hline \multicolumn{5}{|l|}{ Mothers } \\
\hline $\mathrm{ICU}^{\mathrm{a}}$ admission & $1(0.5)$ & $31(10.7)$ & $22.4(3.1-162.6)$ & $<0.01$ \\
\hline Coma & $0(0)$ & $5(1.7)$ & - & 0.02 \\
\hline Transfusion & $1(0.5)$ & $10(3.5)$ & $7.3(0.9-56.4)$ & 0.01 \\
\hline Eclampsia & $0(0)$ & $31(10.7)$ & - & $<0.01$ \\
\hline Cesarean section & $13(6.2)$ & $190(65.3)$ & $10.5(6.2-18.0)$ & $<0.01$ \\
\hline \multicolumn{5}{|l|}{ Newborns } \\
\hline NICU admission ${ }^{b}$ & $32(15.4)$ & $131(45.6)$ & $3.0(2.1-4.2)$ & $<0.01$ \\
\hline Stillbirth & $1(0.5)$ & $29(9.9)$ & $20.9(2.9-151.9)$ & $<0.01$ \\
\hline Low birth weight & $31(15.0)$ & $144(50.0)$ & $3.3(2.4-4.7)$ & $<0.01$ \\
\hline APGAR $<7$ at $5 \min ^{c}$ & $21(10.1)$ & 67 (25.6) & $2.5(1.6-4.0)$ & $<0.01$ \\
\hline
\end{tabular}

${ }^{\mathrm{a}} \mathrm{ICU}=$ Intensive Care Unit

${ }^{b} \mathrm{NICU}=$ Neonatal Intensive Care Unit

cExcluding stillbirths 
Table 4 Maternal and neonatal outcomes by length of delay for preeclamptic and non-preeclamptic women

\begin{tabular}{|c|c|c|c|c|c|c|}
\hline & \multicolumn{3}{|l|}{ Non-Preeclamptic } & \multicolumn{3}{|l|}{ Preeclamptic } \\
\hline & Delay < 6 h: $\mathrm{n}^{\mathrm{a}}(\%)$ & Delay $\geq 6$ h: n (\%) & $p$-value & Delay < 6 h: n (\%) & Delay $\geq 6$ h: n (\%) & $p$-value \\
\hline \multicolumn{7}{|l|}{ Mothers } \\
\hline ICU admission & $1(0.7)$ & $0(0.0)$ & 0.45 & $9(6.9)$ & $11(10.9)$ & 0.28 \\
\hline Coma & $0(0.0)$ & $0(0.0)$ & & $1(0.8)$ & $1(1.0)$ & 0.86 \\
\hline Transfusion & $1(0.7)$ & $0(0)$ & 0.45 & $5(3.9)$ & $2(2.0)$ & 0.41 \\
\hline Eclampsia & no cases & no cases & & $13(9.9)$ & $9(9)$ & 0.81 \\
\hline Cesarean section & $7(4.9)$ & $5(10.4)$ & 0.19 & $80(61.1)$ & $66(65.4)$ & 0.50 \\
\hline \multicolumn{7}{|l|}{ Newborns } \\
\hline NICU admission & $18(12.8)$ & $9(18.8)$ & 0.32 & $52(40.9)$ & $44(43.6)$ & 0.69 \\
\hline Stillbirth & $0(0.0)$ & $1(2.1)$ & 0.96 & $19(14.5)$ & $6(5.9)$ & 0.03 \\
\hline Low birth weight $(<2500 \mathrm{~g})$ & $22(15.7)$ & $5(10.4)$ & 0.35 & $65(50.0)$ & $46(46.0)$ & 0.55 \\
\hline APGAR $<7$ at 5 min & $12(8.5)$ & $7(14.6)$ & 0.24 & $46(35.1)$ & 30 (29.7) & 0.36 \\
\hline
\end{tabular}

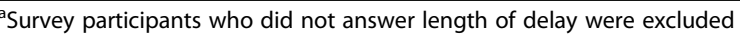

shorter, reflecting the impact of a subset of women with exceptionally long delays. The vast majority of participants had accessed antenatal care, and yet few could identify any warning signs of preeclampsia. Almost one fifth of preeclamptic participants experienced a twenty-four-hour delay in accessing health care after symptoms started. These very long delays were primarily attributable to long first delays, over thirteen hours after symptoms developed, on average, for this group. Third (triage/health facility) delays were also significantly longer in this group, though that may have been attributable to so many in the non-preeclamptic group arriving at the hospital in advanced labor. Second (transport) delays were comparable in the two groups. Preeclamptic women did not have shorter delays to accessing care, even if they lived relatively close to the hospital. Large proportions of women experienced adverse clinical outcomes, including eclampsia and ICU admission for mothers, and NICU admission and stillbirth for newborns.

Few studies examining the Three Delays have attempted to quantify the length of time for each delay. Our findings are generally consistent with those from comparable prior studies. Researchers in India found an average first delay of eight hours among cases of maternal mortality, compared to a two-hour first delay among controls [7]. Researchers in The Gambia and Malawi found first delays among a minority of cases of maternal death, ranging from two days to a month. [22, 23] A recently published study from Ethiopia found very long delays, averaging more than five days, for women experiencing danger signs of preeclampsia [24].

Although we had expected to identify subgroups of women who were more likely to experience delays, we found no demographic factors associated with longer delays. This lack of association may reflect several possibilities unique to the Haitian context. The vast majority of women in this study were poor and lacked formal employment. Poverty creates an overwhelming barrier to access for all mothers, perhaps rendering other associations to longer delays less important. We found a trend towards shorter delay among preeclamptic women with better economic status ( $4.9 \mathrm{~h}$ versus $15.2 \mathrm{~h}$ ), although this did not reach statistical significance, likely given the small number of women in our sample $(n=25)$ who reported faring well economically. Economic factors may have similarly limited access for the women in our study [14] even though geographic distances were relatively short.

The study aimed to identify the role of delayed access to care in poor clinical outcomes for mothers or babies. However, the association between long delays to care and poor clinical outcomes was not clearly evident from the data. Difficulties in assessing delay may have led to an under-reporting of delay for preeclamptic women. The study sample size may have been insufficient to find real associations that do exist. Additionally, the generally low economic status of participants and the difficulty they faced in finding health care may have minimized differences between the delayed and not delayed groups. Finally, neonatal death was not able to be accurately identified in this study, due to the inability to track neonatal outcomes after the time of survey administration. However, it is likely that neonatal deaths, even if accurately reported, would have been too rare to permit detection of major differences among the groups.

Long transportation delays were uncommon among both the preeclamptic and non-preeclamptic groups in our study. Prior studies of maternal mortality and the Three Delays Model in a rural context have focused on the distance between women's homes and delivery facilities as a major factor in both first and second delays $[5,6,11,13,22,25-27]$. The long delays we found among preeclamptic women living relatively close to the 
hospital may improve understanding of how living short distances from a facility may, somewhat counter-intuitively, delay women's decisions to leave home. Most women lived within two to five kilometers of a hospital; however, the effects of urban congestion, including traffic and transport difficulties may have contributed to longer delays. Some neighborhoods close to the CRUO hospital routinely experience high levels of violence, and travel may be too dangerous during nighttime hours, which also could have affected delays. However, some studies have found that women's decisions to leave home for facility birth are unaffected by distance when health facilities are less than five kilometers away [13, 28].

If distance is not a main contributing factor, then what factors determine how urban women and their families make decisions about seeking emergency care? In addition to economic concerns, our study highlights the importance of prioritizing the quality of ANC to identify, treat, refer, and educate higher risk patients such as the preeclamptic mothers studied here, who reported little understanding of danger signs and the importance of seeking care. A lack of understanding of the gravity of their symptoms might explain many women's long first delay at home prior to leaving to seek care. Other studies have found similarly low levels of knowledge of preeclampsia danger signs, [24, 29-31] which contributed to delayed access to care [10, 23, 14]. Despite reporting at least four antenatal visits and a hypertension diagnosis, most preeclamptic women in this study were unaware of the specific symptoms that should prompt immediate medical attention. Given this lack of knowledge among the study population, our study identifies needs for improvement in ANC practices in Haiti and potentially in other low resource urban settings.

The measurement of delay represented the most important study limitation. As with all self-reported data, it is unclear to what extent study participants reported delays accurately. Although the interviewers attempted to clarify responses with participants, as well as to triangulate information with family members, it is possible that reported delays were not accurate. There were also challenges for participants in estimating the first delay. The onset of the first delay corresponds to the onset of the emergency, which is subjective and specific to the experience of each participant. For women without preeclampsia, who were in labor, the onset of the first delay typically corresponded with the onset of strong contractions, or when their water broke. Moreover, the non-preeclamptic women in our study were not an ideal comparison group as they were a select group of women in spontaneous labor who were admitted just prior to delivery. Fifteen participants in the normal group also stated that they had been diagnosed with preeclampsia during that pregnancy, and some of them had elevated blood pressure readings on admission. If these women were on the verge of delivering their infant, it is possible that staff did not have the time to distinguish between blood pressures that can be normally elevated during delivery, and those indicating preeclampsia. Misclassification of women by preeclampsia diagnosis could have biased the delays reported by these groups, by artificially lengthening delays in the normal group. It is unlikely that a misclassification of these fifteen participants would have affected the study outcomes. The non-preeclamptic women had shorter delays partly since they were, as a group, closer to delivery than their preeclamptic counterparts. Preeclamptic women's lack of knowledge of danger signs meant that they were unable to identify the start of the delay, possibly leading to reporting artificially shorter delays.

\section{Conclusion}

In the more than twenty years since the seminal study proposing the Three Delays Model, the model has guided critical efforts to reduce maternal and neonatal mortality. Refining this model to include urban women, and the unique delays they face, will serve to include the essential experiences of these women who also sometimes face long delays to care. A renewed focus on the accessibility and quality of maternal health services, including newly published WHO guidelines on antenatal care, [32] provides an opportunity to improve quality and accessibility of these lifesaving services. This study reinforces the urgent need to ensure that urban poor women are included-and prioritized-in these efforts.

\section{Abbreviations \\ ANC: Antenatal care; CRUO: Centre de Référence en Urgences Obstétricales (Obstetric Emergency Referral Center); DHS: Demographic and Health Surveys; ICU: Intensive Care Unit; MSF: Médecins Sans Frontières (Doctors Without Borders); NICU: Neonatal Intensive Care Unit; TBA: Traditional birth attendant; UNFPA: United Nations Population Fund; WHO: World Health Organization}

\section{Acknowledgements}

We thank Médecins Sans Frontières and the Boston University School of Public Health for their support of this research. We thank Annick Lenglet of MSF Holland for her assistance in drafting study protocols and initial study design. We gratefully thank the women and families who participated in the research study.

\section{Availability of data and material \\ The datasets used and/or analyzed during the current study are available from the corresponding author on reasonable request.}

\section{Funding}

The Boston University Women's Guild supported the data collection of this study.

\section{Authors' contributions}

$\mathrm{KH}$ : Conception and design, acquisition of data, analysis and interpretation of data; drafting the manuscript and revising it critically for important intellectual content. Gave final approval of the version to be published. 
MB: Conception and design, analysis and interpretation of data; revising manuscript critically for important intellectual content. Gave final approval of the version to be published.

MBD: Conception and design, analysis and interpretation of data; revising manuscript critically for important intellectual content. Gave final approval of the version to be published.

DP: Conception and design, analysis and interpretation of data; revising the manuscript critically for important intellectual content. Gave final approval of the version to be published.

LS: Analysis and interpretation of data; revising the manuscript critically for important intellectual content. Gave final approval of the version to be published.

LB: Data acquisition; revising the manuscript critically for important intellectual content. Gave final approval of the version to be published. RJC: Conception of the study; revising the manuscript critically for important intellectual content. Gave final approval of the version to be published. ED: Conception and design, analysis and interpretation of data; drafting the manuscript and revising it critically for important intellectual content. Gave final approval of the version to be published.

\section{Ethics approval and consent to participate}

The study was approved by the Institutional Review Board of Boston University Medical Center (IRB number H-32880), the Ethics Review Board of Médecins Sans Frontières (\#1425), and the Haiti Ethics Review Board. Consent forms were read aloud to participants and written consent was obtained.

\section{Consent for publication}

Not applicable.

\section{Competing interests}

The authors declare they have no competing interests.

\section{Publisher's Note}

Springer Nature remains neutral with regard to jurisdictional claims in published maps and institutional affiliations.

\section{Author details}

${ }^{1}$ Médecins Sans Frontières and Boston University School of Public Health, 715 Albany Street, Boston 02118 USA. ${ }^{2}$ Boston University School of Public Health, Boston, USA. ${ }^{3}$ University of New England, Portland, USA. ${ }^{4}$ Médecins Sans Frontières, Amsterdam, the Netherlands. ${ }^{5}$ Médecins Sans Frontières, Addis Ababa, Ethiopia. ${ }^{6}$ Medical School of the State University of Haiti, Port-au-Prince, Haiti.

\section{Received: 15 November 2017 Accepted: 2 August 2018}

\section{Published online: 20 August 2018}

\section{References}

1. Raghuraman N, March Ml, Hacker MR, Modest AM, Wenger J, Narcisse R, et al. Adverse maternal and fetal outcomes and deaths related to preeclampsia and eclampsia in Haiti. Pregnancy Hypertens An Int J Women's Cardiovasc Heal. 2014:4:279-86.

2. Small MJ, Kershaw T, Frederic R, Blanc C, Neale D, Copel J, et al, Characteristics of preeclampsia- and eclampsia-related maternal death in rural Haiti. J Matern Fetal Neonatal Med. 2005;18:343-8. https://doi.org/10. 1080/14767050500312433.

3. Say L, Chou D, Gemmill A, Tunçalp Ö, Moller A-B, Daniels J, et al. Global causes of maternal death: a WHO systematic analysis. Lancet Glob Heal. 2014:2:e323-33. https://doi.org/10.1016/S2214-109X(14)70227-X

4. Alexandre PK, Saint-Jean G, Crandall L, Fevrin E. Prenatal care utilization in rural areas and urban areas of Haiti. Rev Panam Salud Pública. 2005:18:8492. https://doi.org/10.1590/S1020-49892005000700002.

5. Thaddeus S, Maine D. Too far to walk: maternal mortality in context. Soc Sci Med. 1994;38:1091-110. http://www.ncbi.nlm.nih.gov/pubmed/8042057. Accessed 10 Feb 2014

6. Gabrysch S, Campbell OMR. Still too far to walk: literature review of the determinants of delivery service use. BMC Pregnancy Childbirth. 2009;9:34. https://doi.org/10.1186/1471-2393-9-34

7. Ganatra BR, Coyaji KJ, Rao VN. Too far, too little, too late: a communitybased case-control study of maternal mortality in rural West Maharashtra. India Bull World Health Organ. 1998;76:591-8. http://www.pubmedcentral. nih.gov/articlerender.fcgi?artid=2312494\&tool=pmcentrez\&rendertype= abstract. Accessed 11 Sep 2014

8. McNamee P, Ternent L, Hussein J. Barriers in accessing maternal healthcare: evidence from low-and middle-income countries. Expert Rev Pharmacoecon Outcomes Res. 2009;9:41-8. https://doi.org/10.1586/14737167.9.1.41.

9. Brunson J. Confronting maternal mortality, controlling birth in Nepal: the gendered politics of receiving biomedical care at birth. Soc Sci Med. 2010; 71:1719-27. https://doi.org/10.1016/j.socscimed.2010.06.013.

10. Killewo J, Anwar I, Bashir I, Yunus M, Chakraborty J. Perceived delay in healthcare-seeking for episodes of serious illness and its implications for safe motherhood interventions in rural Bangladesh. J Health Popul Nutr. 2006;24:403-12. http://www.pubmedcentral.nih.gov/articlerender.fcgi?artid= 3001144\&tool=pmcentrez\&rendertype=abstract. Accessed 10 Sep 2014

11. Gething PW, Johnson FA, Frempong-Ainguah F, Nyarko P, Baschieri A, Aboagye $\mathrm{P}$, et al. Geographical access to care at birth in Ghana: a barrier to safe motherhood. BMC Public Health. 2012;12:991. https://doi.org/10.1186/ 1471-2458-12-991.

12. Filippi V, Richard F, Lange I, Ouattara F. Identifying barriers from home to the appropriate hospital through near-miss audits in developing countries. Best Pract Res Clin Obstet Gynaecol. 2009;23:389-400. https://doi.org/10. 1016/j.bpobgyn.2008.12.006.

13. Gabrysch S, Cousens S, Cox J, Campbell OMR. The influence of distance and level of care on delivery place in rural Zambia: a study of linked national data in a geographic information system. PLoS Med. 2011;8:e1000394. https://doi.org/10.1371/journal.pmed.1000394.

14. Essendi H, Mills S, Fotso J-C. Barriers to formal emergency obstetric care services' utilization. J Urban Health. 2011;88(Suppl 2):S356-69. https://doi. org/10.1007/s11524-010-9481-1.

15. Bayu H, Fisseha G, Mulat A, Yitayih G, Wolday M. Missed opportunities for institutional delivery and associated factors among urban resident pregnant women in South Tigray zone. Ethiopia: a community-based follow-up study Glob Health Action. 2015;8:28082. http://www.ncbi.nlm.nih.gov/pubmed/ 26361348. Accessed 7 Jun 2016

16. Hailu $\mathrm{D}$, Berhe $\mathrm{H}$. Determinants of institutional childbirth service utilisation among women of childbearing age in urban and rural areas of Tsegedie district. Ethiopia Midwifery. 2014; https://doi.org/10.1016/..midw.2014.03.009.

17. Nahar S, Banu M, Nasreen HE. Women-focused development intervention reduces delays in accessing emergency obstetric care in urban slums in Bangladesh: a cross-sectional study. BMC Pregnancy Childbirth. 2011;11:11. https://doi.org/10.1186/1471-2393-11-11.

18. Watts J. Haiti making good progress in health but challenges remain. Lancet. 2014;384:1413-4. https://doi.org/10.1016/S0140-6736(14)61835-3.

19. Cayemittes M, Busangu MF, de Dieu Bizimana J, Barrère B, Blaise Sévère $V$, Charles C, et al. Enquête Mortalité, Morbidité et Utilisation des Services, Haïti, Calverton, Maryland. USA. 2012;2013

20. Medecins Sans Frontieres. Maternity Data Tool. 2013

21. United Nations Population Fund. Setting standards for emergency obstetric and newborn care | UNFPA - United Nations Population Fund. 2014. http:// www.unfpa.org/resources/setting-standards-emergency-obstetric-andnewborn-care. Accessed 20 Dec 2016

22. Combs Thorsen V, Sundby J, Malata A. Piecing together the maternal death puzzle through narratives: the three delays model revisited. PLoS One. 2012; 7:e52090. https://doi.org/10.1371/journal.pone.0052090.

23. Jammeh A, Sundby J, Vangen S. Barriers to emergency obstetric care services in perinatal deaths in rural Gambia: a qualitative in-depth interview study. ISRN Obstet Gynecol. 2011;2011:981096. https://doi.org/10.5402/2011/981096.

24. Gudu W. Prodromal symptoms, health care seeking in response to symptoms and associated factors in eclamptic patients. BMC Pregnancy Childbirth. 2017;17:87. https://doi.org/10.1186/s12884-017-1272-1.

25. Cham M, Sundby J, Vangen S. Maternal mortality in the rural Gambia, a qualitative study on access to emergency obstetric care. Reprod Health. 2005:2:3. https://doi.org/10.1186/1742-4755-2-3.

26. Kyei NNA, Campbell OMR, Gabrysch $\mathrm{S}$. The influence of distance and level of service provision on antenatal care use in rural Zambia. PLoS One. 2012;7: e46475. https://doi.org/10.1371/journal.pone.0046475.

27. Mselle LT, Kohi TW, Mvungi A, Evjen-Olsen B, Moland KM. Waiting for attention and care: birthing accounts of women in rural Tanzania who developed obstetric fistula as an outcome of labour. BMC Pregnancy Childbirth. 2011;11:75. https://doi.org/10.1186/1471-2393-11-75.

28. Mwaliko E, Downing R, O'Meara W, Chelagat D, Obala A, Downing T, et al. "Not too far to walk": the influence of distance on place of delivery in a 
western Kenya health demographic surveillance system. BMC Health Serv Res. 2014;14:212. https://doi.org/10.1186/1472-6963-14-212.

29. Maseresha N, Woldemichael K, Dube L, Campbell O, Graham W, Thaddeus S, et al. Knowledge of obstetric danger signs and associated factors among pregnant women in Erer district, Somali region. Ethiopia BMC Womens Health. 2016;16:30. https://doi.org/10.1186/s12905-016-0309-3.

30. Kabakyenga JK, Östergren P-O, Turyakira E, Pettersson KO, Starrs A, Koblinsky $\mathrm{M}$, et al. Knowledge of obstetric danger signs and birth preparedness practices among women in rural Uganda. Reprod Health. 2011;8:33. https:// doi.org/10.1186/1742-4755-8-33.

31. Gebre M, Gebremariam A, Abebe TA. Birth preparedness and complication readiness among pregnant women in Duguna Fango District, Wolayta zone. Ethiopia PLoS One. 2015;10:e0137570. https://doi. org/10.1371/journal.pone.0137570.

32. World Health Organization. WHO recommendations on antenatal care for a positive pregnancy experience. World Health Organization; 2016. http:// www.who.int/reproductivehealth/publications/maternal_perinatal_health/ anc-positive-pregnancy-experience/en/. Accessed 16 May 2017.

Ready to submit your research? Choose BMC and benefit from:

- fast, convenient online submission

- thorough peer review by experienced researchers in your field

- rapid publication on acceptance

- support for research data, including large and complex data types

- gold Open Access which fosters wider collaboration and increased citations

- maximum visibility for your research: over $100 \mathrm{M}$ website views per year

At $\mathrm{BMC}$, research is always in progress.

Learn more biomedcentral.com/submissions 